\title{
Comunicação e sociabilidade no Chatroulette: 0 público e o privado na roleta de imagens
}

\author{
Communication and sociability on the Chatroulette: the public and the \\ private sectors in the image roulette
}

\section{Karla Regina Macena Pereira Patriota ${ }^{[\mathrm{a}]}$, Daniele Araújo Freitas ${ }^{[\mathrm{b}]}$, Júlia Aires Rossiter ${ }^{[\mathrm{c}]}$, Zandra Marina de Holanda Monteiro ${ }^{[\mathrm{d}]}$}

[a] Doutora em Sociologia e Mestre em Comunicação pela Universidade Federal de Pernambuco (UFPE), professora do Programa de Pós-Graduação em Comunicação da Universidade Federal de Pernambuco (PPGCOM/UFPE), Recife, PE - Brasil, e-mail: k.patriota@gmail.com

[b] Graduanda em Publicidade e Propaganda pela Universidade Federal de Pernambuco, aluna do Programa de Iniciação Científica pela Universidade Federal de Pernambuco (UFPE), Recife, PE - Brasil.

[c] Graduanda em Publicidade e Propaganda pela Universidade Federal de Pernambuco (UFPE), bolsista do Programa de Iniciação Científica pela Fundação de Amparo à Ciência e Tecnologia do Estado de Pernambuco (FACEPE), Recife, PE - Brasil.

[d] Graduanda em Publicidade e Propaganda pela Universidade Federal de Pernambuco (UFPE), Recife, PE - Brasil.

\section{Resumo}

A evolução tecnológica vem permitindo, cada vez mais, uma interação maior entre as pessoas. O ciberespaço, lócus onde essas interações materializam-se, contribui para o aumento da velocidade das trocas e a ampliação das possibilidades de conexões. Nesse cenário, surge uma ferramenta de relacionamento nomeada de Chatroulette, que consiste em direcionar, anonimamente, o usuário a outras pessoas, também conectadas, oferecendo ainda a opção next, caso se queira conversar com outros "estranhos" em substituição ao que se apresenta na tela. Neste trabalho, promovemos uma reflexão acerca da comunicação efetuada por meio do Chatroulette e as características que ressaltam a peculiar sociabilidade na web, ao mesmo tempo em que refletimos sobre a sociedade do espetáculo descrita por Debord na década de 1960.

Palavras-chave: Chatroulette. Sociedade do espetáculo. Imagens. Sociabilidade e comunicação em rede.

\section{Abstract}

Technological progress has allowed more and more a greaterinteraction among people. The cyberspace, the locus where these interactions are materialized, contributes to both increasing the speed of trade and expanding the possibilities of connections. In this scenario a relationship tool named Chatroulette arises. It consists of directing anonymously, 
the user to otherpeople who are also connected, while providing the next option, in case you want to chat with other "outsiders" instead of what is on the screen. In this article, we promote a reflection about the communication made through Chatroulette and the features that highlight the peculiar sociability on the web, whilst we reflect about the society of the spectacle described by Debord in the 60s.

Keywords: Chatroulette. Society of the spectacle. Images. sociability and communication network.

\section{Introdução}

Crescemos sonhando com o futuro. Não apenas o nosso, no sentido estrito do tema, mas o futuro tecnológico, espacial, cheio de invenções robóticas que viriam para facilitar a vida de todos, como no desenho animado Os Jetsons. ${ }^{1}$ E mesmo que tudo parecesse muito óbvio: naves que enchiam o espaço aéreo das cidades suspensas, trabalho automatizado, esteiras rolantes que facilitavam o deslocamento, aparelhos de teletransporte, robôs que realizavam todos os desejos de seus proprietários, havia uma natural expectativa de concretização daquilo tudo.

Esse futuro foi contado e recontado em muitos outros desenhos, livros, filmes e séries. Por meio de prognósticos futuristas várias produções como 1984; 2001: uma odisseia no espaço; ${ }^{3}$ Admirável mundo novo $;{ }^{4}$ Matrix; ${ }^{5}$ Cidades do futuro $;{ }^{6}$ Metropolis; ${ }^{7}$ The metropolis of tomorrow; ${ }^{8} \mathrm{O}$ ano $2000^{9}$ e tantas outras, tentavam prever a vida na sociedade, introduzindo no imaginário da maioria das pessoas o que seria o futuro da humanidade. Não obstante o que observamos hoje com relação a alguns acertos, essas obras não conseguiram prever como seria realmente a vida no porvir com a internet, mesmo que reproduzissem mecanismos telecomunicacionais utilizados hoje. $\mathrm{O}$ fato é que a revolução comunicativa que assistimos atualmente não foi calculada, sonhada, ilustrada, nem sequer imaginada. A tecnologia passou a ter uma vertente quase mágica, ressacralizante, alicerçada não na eliminação do individual, nem na exclusiva existência do tecnológico e automatizado, mas na sua reafirmação por meio de uma nova dimensão - uma tecnocultura socializante de cunho essencialmente experimental.

1 Uma "típica" família do século XXI, que residia em um arranha-céu futurista e tinha à sua disposição robôs e aparelhos supermodernos, que tornavam suas vidas mais fáceis e mais ligadas ao tecnológico.

2 Livro publicado em 1949, de George Orwell, que apresenta uma metáfora sobre o poder e as sociedades modernas. O autor, enfermo, o redigiu animado de um sentido de urgência em avisar os seus contemporâneos, e as gerações futuras, do perigo que corriam de que o Estado controlasse o pensamento dos cidadãos e vigiasse a todos. O autor retratava a teletela como um televisor bidirecional, que perrmitia tanto ver quanto ser visto e que, portanto, via tudo.

3 2001: a space odyssey (1968) - ficção científica, de Stanley Kubrick, que pondera sobre o perigo de dar-se muito controle aos computadores. O filme aborda tecnologia, viagens espaciais e as condições humanas da sociedade do futuro.

4 Brave new world (1932) - livro de Aldous Huxley que prevê uma sociedade organizada por castas, na qual as pessoas são precondicionadas biologicamente e condicionadas psicologicamente a viverem em harmonia com as leis e regras sociais. A sociedade desse "futuro", além de ser tecnológica, não possui a ética religiosa e os valores morais que regem a sociedade atual.

5 The matrix (1999) - primeiro filme da trilogia que narra a história do "Escolhido", recrutado por um pequeno grupo de rebeldes do futuro que lutam contra uma realidade virtual que controla a vida de todos.

6 Future cities: homes and living into the 21st century (1979) (da coleção World of the future) - de autoria de Kenneth William Gatland e David Jefferis, o livro descreve o futuro das cidades com a tecnologia. Suas previsões ilustradas aproximam-se de muitas coisas vistas hoje.

7 Filme de 1927 de autoria de Fritz Lang. Na referida obra, a paisagem urbana do ano 2000 é dominada por carros voadores e fortalezas dez vezes mais altas do que os grandes arranha-céus da atualidade e clones humanos são escravizados.

8 Livro de Hugh Ferriss, publicado originalmente em 1929, é um trabalho dividido em três partes: cidades de hoje, tendências projetadas, e o imaginário das metrópoles.

9 Livro de Herman Khan, publicado na década de 1970, que virou best-seller no Brasil. A obra alçou a futurologia, inicialmente, à condição de ciência e logo depois a rebaixou ao status de piada. O autor não teve nem o tempo a seu favor. O que previu como futuro não se concretizou nem de perto. Seu livro prognosticou sobre o papel central que os computadores teriam na vida moderna, mas a internet, ou algo semelhante, nem sequer foi pensada. 
Esse processo, antes inimaginável, promoveu uma difusão acelerada de conhecimentos e informações, mas também exigiu reavaliação e reestruturação da comunicação e de seus pressupostos teóricos. Como bem lembra Biernazki (2000), a cultura e a informação ultrapassaram fronteiras, portanto é cada vez mais evidente a globalização dos diversos setores da sociedade, entre eles a comunicação.

Com efeito, hoje nos deparamos com um mundo totalmente tecnológico, conectado, ligado e interligado em rede, um emaranhado de links que encurtam distâncias e que alteram o nosso entendimento acerca do próximo e do longínquo. Essa lógica, como amplamente propagada por diversos estudiosos da atualidade, remodela a noção de tempo e espaço, materializando-se por meio dos novos modos de se "estar junto" e pela percepção espacial das experiências do fluxo, do instantâneo, do simultâneo. No entanto, ela não se limita a isso e também reconfigura, desconstrói e reconstrói as noções anteriores dos conceitos relacionados à própria comunicação em si, uma vez que o aparecimento da internet provocou impactos substanciais nos diversos setores da vida de qualquer indivíduo.

É fundamental ressaltar, por conseguinte, que o surgimento da internet mudou toda a forma de pensar e agir de uma sociedade. Não são impactados por ela, apenas, aqueles que detêm o conhecimento dos sistemas e que sabem como usar o computador. Esses indivíduos completamente envolvidos em um universo de gírias computacionais e vocabulários técnicos, rapidamente incorporados à linguagem do dia a dia, também influenciam àqueles que, apesar de não usarem a web, estão ao seu redor. Isso acontece porque a própria internet já está incorporada ao cotidiano das pessoas, afetando-as em diferentes graus e direta ou indiretamente (NICOLACI-DACOSTA, 2005).

\section{Comunicação em rede: as novas sociabilidades na internet}

Dizer que o homem está fadado a viver na coletividade é lugar-comum, afinal trata-se de ser eminentemente social. Contudo, apesar de não se saber exatamente quando se iniciou a sociedade, e independente das teorias defendidas acerca disso, o que se quer ressaltar aqui é que a comunicação é um agente profundamenteinfluenciador e transformador em qualquer processo de sociabilidade. ${ }^{10}$ De fato, as diversas formas comunicacionais contribuíram demasiadamente nesse processo: os desenhos, os gestos, a fala e o alfabeto, apenas para citar alguns, fazem da comunicação um fenômeno histórico, social e antropológico. Ao comunicar-se, o homem revela-se como pessoa e descobre o que está ao seu redor. A interação com o outro é intrínseca à sua existência enquanto ser e, consequentemente, inúmeras ferramentas são criadas e aperfeiçoadas, ao longo do tempo, com o intuito de efetivar tal relação.

Soma-se a isso o fato de que a evolução tecnológica vem permitindo, cada vez mais, uma interação maior entre as pessoas. Como pontuamos anteriormente, o surgimento da internet, por exemplo, possibilitou o estabelecimento de novas formas de comunicação, inexistindo, agora, barreiras geográficas e/ou distâncias reais capazes de impedir o processo comunicacional. A partir disso, as relações deixam de ser estabelecidas única e exclusivamente no campo do "real" para serem construídas também na virtualidade. ${ }^{11} \mathrm{~A}$ Web $2.0^{12}$ é uma plataforma de destaque nesse quesito, pois dá suporte aos diversos sites de relacionamento, ${ }^{13}$ ampliando e acrescentando múltiplos e novos aspectos aos antigos conceitos de sociabilidade, partilha e comunidade. Tudo isso porque uma das grandes responsáveis pelo sucesso da Web 2.0, como a conhecemos hoje, é a possibilidade

\footnotetext{
${ }^{10}$ Conceito que conjetura um vínculo social, uma conexão, um elo básico e relações sociais focadas em grupos de relacionamentos.

${ }^{11}$ De acordo com Santos et al. (2009, p. 6), o termo "real” está relacionado a "todas as coisas que existem", sendo, portanto, propriedade do que é real, atributo do existente. Para os autores, uma vertente de estudiosos dessa matéria aceita a diferenciação entre uma realidade extra-mentis e outra intra-mentis; esta é o universo das coisas "imaginárias", e aquela, o universo das coisas “tangíveis". Nesse caso, a comunicação virtual é também real e verdadeira em si mesma, e não nega sua natureza, sendo o real em potencial, como faculdade.

${ }^{12}$ É a segunda geração da World Wide Web, sendo conceituada como a web colaborativa. O foco é o usuário, sua socialização e interação com os outros por meio do compartilhamento e da criação conjunta de conteúdo, tornando o ambiente mais dinâmico.

${ }^{13}$ Como principais exemplos temos: Orkut, Twitter, Facebook, além de diversos blogs, fotologs e tantos outros.
} 
de geração/difusão de informações (já que todos podem ser produtores de conteúdo) e a noção aflorada da inteligência coletiva, ${ }^{14}$ que agora faz parte do nosso cotidiano.

É justamente a partir da premissa de que todos têm algo a dizer, ou a mostrar, que as novas sociabilidades da contemporaneidade ganham fôlego na internet - o celeiro da inteligência coletiva. Segundo Castells (1999), é inegável a importância das redes sociais como responsáveis pela manutenção de relacionamentos e da sociabilização ${ }^{15}$ nos dias atuais.

Por conseguinte, as redes sociais na internet acabam por ser compreendidas como os laços criados entre atores sociais com interesses e valores em comum, por meio da interação, viabilizada por computadores, que se estrutura na troca de mensagens dos atores entre si e na cooperação que tem como resultado a união de ideias e recursos. O ciberespaço, lócus em que essas trocas "materializam-se", contribui para o aumento da velocidade das trocas e a ampliação das possibilidades de conexões. É importante destacar que os blogs, microblogs e sites de relacionamento, por exemplo, apenas facilitam o surgimento e a manutenção dos laços, mas são os usuários, os atores sociais, que constroem as redes sociais (SOUZA, 2009, p. 17).

Nas redes sociais como Orkut, Facebook, Twitter, Flickr, etc. - todas de essência comunicativa verbal - é possível perceber que a sociabilidade transcende a mera instauração de relacionamentos ou comunicação. Nelas, a linguagem imagética firma-se como a principal forma de comunicação por sua aparente objetividade e clareza. Contudo, é válido salientar que emoções comandam processos mentais e que estes determinam a forma como nos relacionamos com o mundo e estabelecemos relações entre os estímulos externos e o nosso repertório de vivências. Por isso, não é difícil perceber nesses novos espaços de sociabilidade um grande culto à vaidade. As pessoas expõem-se na rede não só com o objetivo de relacionar-se, mas também de "mostrarse". Segundo Primo (2009, p. 8), a web possibilita que seus usuários mostrem-se mais atrativos do que realmente são, já que a maior parte dos perfis das redes sociais é construída a partir de fotos e textos autobiográficos-o que autoriza a seleção meticulosa apenas dos aspectos positivos.

A nosso ver, éjustamente aqui, na ampliação das práticas forjadas de exposição da intimidade no meio digital, que novas formas de sociabilidade e relacionamentos firmam-se nos dias atuais. Nota-se, dessa maneira, uma convergência entre uma cultura narcísica e atitudes exibicionistas que corroboram na consolidação de uma sociedade do espetáculo (DEBORD, 1997, p. 13). Tão somente porque o conceito de espetáculo transcende o que estamos habituados a aceitar e o que consta no dicionário: "perspectiva; contemplação; representação teatral; diversão pública em circos; cena ridícula; escândalo" (MICHAELIS, 2008).

A própria raiz semântica (latina) de espetáculo (spetaculum) tem como sentido e essência, tudo o que atrai e prende o olhar e a atenção. Ou, como Gomes (2003 apud MAFRA, 2006, p. 55) explana: "specto (spectare) como olhar, ver, considerar, observar; spectaculum como o que se dá a ver, o aspecto, o espetáculo; spectatio (spectationis) como o ato de olhar, o desfrute visual, a visão de algo; e o spectator (spectatoris) como quem vê, o observador, o espectador". Muito embora detentora de várias possibilidades, a definição de espetáculo nos traz a dimensão de algo a ser contemplado, visto, observado. Em outras palavras, algo que provoca e gera a necessidade e a instauração de uma relação entre acontecimento e espectador, que chama a atenção e prende o olhar. "Em todos os casos, a interação evento-espectador se afirma e o sentido do olhar comparece com prioritária menção" (RUBIM, 2002, p. 7).

Soma-se a isso o fato de que, na nova sociabilidade que desponta na web, o individualismo atinge o ápice, porém, o olhar do outro é fundamental para se fazer ser. Utilizando-se da psicanálise para se conhecer as novas relações presentes na cultura do narcisismo, percebe-se que "o sujeito da cultura do espetáculo encara o outro apenas como um objeto para o seu usufruto" (BIRMAN, 2000, p. 25), ou seja, focar no eu faz do outro objeto para satisfações egoístas.

\footnotetext{
${ }^{14}$ Segundo Lévy (1998), trata-se de "uma inteligência distribuída por toda parte [...]. Ninguém sabe tudo, todos sabem alguma coisa, todo o saber está na humanidade". Com o advento da internet esse saber é sociabilizado e, portanto, disponível a todos.

15 Presente na adaptação dos indivíduos aos novos grupos, ao mesmo tempo em que os torna membros funcionais deles - que aceitam a cultura da web e incorporam o ethos dos que ocupam o mesmo espaço.
} 
$\mathrm{Na}$ atual cultura do narcisismo e da exaltação gloriosa do eu, as mídias se destacam como instrumentos fundamentais para a afirmação egóica. A cultura da imagem é o domínio da aparência como possibilidade de sedução e fascínio do outro. A exibição midiática transformase no lema essencial da existência, cobrando implacavelmente a performance. As mídias constroem o espaço público pelas imagens: ser e parecer se identificam no discurso narcísico do espetáculo (DUPAS, 2003, p. 47).

Com efeito, essa exposição continuada do indivíduo nas plataformas digitais revela-se, como bem ressalta Bruno (2005, p. 63), em uma "cultura regida pelo ideal de ego, a vida privada se volta para fora, em busca de um olhar que a reconheça e ateste sua visibilidade". Justamente por isso, os postulados de "intimidade e visibilidade" atrelam-se e enlaçam-se sendo amplamente expandidos. Logo, a necessidade de ser avaliado, a busca por autoafirmação, faz com que muitas vezes os indivíduos desvaneçam-se da própria privacidade. Surge, assim, um contraponto entre privacidade e alteridade ${ }^{16}$ que permeia as sociabilidades dos dias atuais.

\section{A sociabilidade no Chatroulette: o público e o privado na roleta}

Com o intuito de promoveruma comunicação interativa e visual, por meio do compartilhamento de imagens, conhecimentos e troca de experiências, foi criada pelo jovem russo, de apenas 17 anos, Andrey Ternovskiy, a rede social Chatroulette ou "roleta de conversas". O aplicativo permite que seus usuários possam interagir com pessoas do mundo inteiro; para isso, basta o internauta acessar o site chatroulette.com e dar o play (MERIGO, 2010). ${ }^{17}$

O mecanismo consiste basicamente em direcionar o usuário a outras pessoas, também conectadas, oferecendo ainda a opção next, caso se queira conversar com outros "estranhos" em substituição ao que se apresenta na tela. A probabilidade de encontrar o mesmo utilizador com quem o usuário já conversou é mínima, uma vez que o sistema faz o direcionamento de forma aleatória e que mais de 35 mil pessoas em todo o mundo poderão estar conectadas ao mesmo tempo.

No Chatroulette, as conversas são realizadas por intermédio da webcam, e seu diferencial de criação consiste exatamente em não apenas falar, mas também ver um "estranho" aleatório que o sistema conecta automaticamente à página aberta do usuário. Apesar de pouco desenvolvido, ${ }^{18}$ o aplicativo apresenta-se como um grande sucesso e ganha a cada dia mais adeptos ao redor do mundo. Quando lançado só possuía dez usuários, todos amigos do jovem russo. Com um pouco mais de três meses de existência a audiência vem crescendo exponencialmente, o que indica ser apenas uma questão de tempo para que o Chatroulette torne-se uma grande febre mundial (CURVELO, 2010).

Para acessar o site não é necessário realizar cadastro ou responder a qualquer tipo de questionário, basta simplesmente conectar-se ao sistema de forma totalmente anônima. Apesar de ser um aplicativo rápido e fácil de utilizar, a falta de cadastro impossibilita o controle dos usuários, dando margem à pedofilia, à pornografia e a outros crimes virtuais. Esse tipo de comportamento online, de acordo com Ballone (2003), permite concluir que um mesmo instrumento que dissipa fronteiras e revoluciona o paradigma comunicacional, também pode ser utilizado de forma patológica. ${ }^{19}$

$\mathrm{O}$ indivíduo que se propuser a encarar a "brincadeira" 20 deverá ir preparado para ver de tudo, desde pessoas com fantasias até desconhecidos sem roupa alguma. A ideia central de Ternovskiy era de poder conectar-se às pessoas de qualquer lugar do globo, e não apenas aos seus amigos. Desde então, milhares de internautas vêm aderindo à novidade.

\footnotetext{
${ }^{16}$ Concepção de que todo homem social interage e interdepende de outros indivíduos. Assim, a existência do "eu-individual” só é viável e possível mediante o contato com o outro.

${ }^{17}$ Informação obtida no site: <http://www.proxxima.com.br/portal/post/9452>. Consultado em 4 de março de 2010.

${ }^{18}$ É perceptível a forma "amadora" e não comercial da ferramenta.

${ }^{19}$ Prado (1999) pontua alguns fatores que estão relacionados ao uso patológico da internet, são eles: anonimato, segurança, facilidade de uso e acesso, suporte social, satisfação sexual, personalidade virtual e reconhecimento e poder.

${ }^{20} \mathrm{Na}$ internet alguns falam em "brincar" no Chatroulette.
} 
O conceito do aplicativo já foi alvo de grandes discussões entre estudiosos. Alguns defendem que tais redes sociais, e a internet em si, podem até mesmo causar dependência e, assim como King (1996), acreditam que se dão certo, é justamente pelos novos valores que as sociedades assumem diante do juízo sobre as novas sociabilidades - que legitimam e encorajam o contato com pessoas desconhecidas no ambiente online.

Por tratar-se de uma comunicação mediada por computadores, o entendimento das relações que se firmam no ciberespaço é permeado por características específicas. Segundo Primo (2007), as interações em redes sociais podem ser reativas ou mútuas, de acordo com a relação que se estabelece entre as partes envolvidas. As interações reativas são restritas e causais, havendo poucas opções aos agentes do processo. Exatamente como acontece no Chatroulette. Ou seja, na roleta de "amigos"21 proposta pelo site não são possíveis muitas variações de resposta ao sistema: ou aceita-se a conversa com "aquele estranho" ou passa-se para o "próximo estranho". Portanto, trata-se de um tipo de interação totalmente baseado na previsibilidade e na automatização das trocas.

Já as interações mútuas, de acordo com a visão de Primo (2007), são pautadas pelas possibilidades de construções criativas e negociadas entre os agentes. Elas firmam-se de maneira aberta, sendo inúmeras as formas como a resposta pode ser construída e a interação mantida, ou não, a partir dali. Interações mútuas passam por constantes problematizações que podem ser solucionadas por meio de negociações sucessivas. O que não se aplica ao Chatroulette na sua forma atual, em virtude da velocidade e do formato da ferramenta.

Do ponto de vista temporal, Primo (2007) ainda considera as interações no espaço virtual como sincronas e assíncronas. A primeira, observada no Chatroulette, aproxima-se de um contato real (já que as pessoas são vistas na tela do computador simultaneamente) e, por conseguinte, a expectativa de resposta é imediata. Já nas interações assíncronas, inviáveis em roletas de chat, não se espera uma resposta imediata- mente, como acontece, por exemplo, nas discussões abertas nos fóruns de diversas comunidades.

Obviamente, usar o Chatroulette pela primeira vez pode causar certo receio, já que não se sabe, seguramente, o que aparecerá do outro lado da tela. Sustos e risos são inevitáveis. Ao iniciar o chat podem saltar à tela, além das pessoas (vestidas ou não), cenas engraçadas e/ou bizarras: cantores e músicos, por exemplo. De fato, esses são os perfis que mais aparecem no chate, dependendo do horário (atrelado aos fusos de cada país), uma parcela significativa dos usuários está em busca de exibicionismo pornográfico por meio da exposição de seus órgãos genitais.

Diferentemente das redes sociais que criam os perfis dos usuários para identificá-los e, assim, estabelecerem ligações com os outros usuários conhecidos ou de interesse para relacionamentos, o Chatroulette ressalta o anonimato, o desconhecido e a aleatoriedade como os grandes diferenciais. Na maioria das vezes, as interações duram apenas alguns segundos, com acenos, risos, "dancinhas" e sustos. O que raramente acarreta o estabelecimento de diálogos lógicos, sérios e, muito menos, duradouros.

Tendo em vista esse novo ambiente como meio de análise, levanta-se uma discussão em torno de conceitos como visibilidade e privacidade no meio online. É possível, a partir disso, reconhecer uma mudança no que se refere às noções de público e privado no mundo contemporâneo, já que não há mais uma linha que delimite seguramente essas esferas. Como bem pontua Bruno (2005, p. 55), é “a emergência recente de uma nova forma de mediação entre o público e o privado, ${ }^{22}$ efetuada pelas tecnologias de comunicação, aí incluídas tanto a mídia de massa quanto as novas mídias digitais".

A evasão da privacidade, todavia, parece não atormentar quem está inserido nesse tipo de virtualidade, pois o número de participantes no meio é crescente. Por alheamento, ou não, a exposição da vida privada dá-se, dentre outros aspectos, pelo que já foi mencionado (o narcisismo, a valoração do ego, a visibilidade, a alteridade, entre outros) e essa é a realidade aplicável ao Chatroulette. Com pouco tempo

\footnotetext{
${ }^{21}$ O conceito de amigo dentro dos sites de relacionamentos dá-se de maneira diferente do mundo offline. Muitas vezes, a relação não existe fora da web e/ou a afinidade é pouca para tanto (SOUZA, 2009, p. 15).

${ }^{22}$ Se levarmos em conta que o privado se opõe ao público, teremos a noção de privado como tudo aquilo que é de caráter oculto, secreto, reservado.
} 
de existência, o site já tem um número expressivo de acessos e, de certa forma, grande parte dos usuários apresenta características pertinentes ao comportamento narcísico, em que a necessidade de visibilidade sobressai-se à privacidade.Com efeito, em ambientes assim, os atos mais ordinários na vida dos humanos auferem força à nova realidade. É o que Baudrillard (2002, p. 9) denomina de vivissecção, estágio em que todo o imaginário submerge, sobrando somente uma verificação ilimitada do funcionamento dos seres. Ou seja, para o autor, a exposição excessiva suscita um sentido de platitude, que faz com que atos, anteriormente impregnados de significados, esvaziem-se, convertendo os seus protagonistas em meros ratos de laboratório - comparação que o autor faz com a exposição humana nos reality shows. Baudrillard (2002) crê que o que se tem hoje é uma metáfora esvaziada da realidade, a partir de suportes como a internet - lugar onde todos se mostram muito e por isso acabam não sendo vistos: "Há duas maneiras de desaparecer: ou exigimos não sermos vistos (é a problemática atual do direito à imagem) ou caímos no exibicionismo delirante da própria mediocridade" (BAUDRILLARD, 2002, p. 8).

Não surpreende, portanto, que as novas e amplas possibilidades de socialização disponibilizadas na Web 2.0 gerem nas pessoas uma necessidade de exposição na mídia. Como argumentamos antes, vivese em uma sociedade do espetáculo em que "tudo que era vivido diretamente tornou-se representação" (DEBORD, 1997, p. 13). E, assim, a flexibilização das fronteiras entre o público e o privado, por meio da exaltação do olhar egoico do indivíduo, fazem surgir novos paradigmas em torno da socialização doindivíduo.

\section{Considerações finais: que tipo de comunicação se estabelece no Chatroulette?}

Marteleto (2001 apud ALCARÁ; DI CHIARA; TOMAÉL, 2005) apresenta as redes sociais como representantes de agrupamentos de participantes autônomos, tendo cada um sua função e identidade cultural. Nesses agrupamentos há o compartilhar de valores e interesses, além da união de ideias e recursos. Para Alcará, Di Chiara e Tomaél (2005), a ideia de rede também nos remete à caça, o que é, em boa parte, no caso das redes sociais, a caça de informação. Traçando um paralelo com o Chatroulette, poderíamos dizer que a comunicação é alicerçada em participantes autônomos, cujo interesse maior é a caça às imagens.

Uma das hipóteses que ancora tal procura pode ser o fato de que a linguagem visual é consagrada pelo imediatismo contemporâneo, por ser abrangente, objetiva, de fácil e rápida assimilação. O ditado popular "uma imagem vale mais do que mil palavras" nunca esteve tão aplicado à realidade, definindo, de forma simples, uma sociedade essencialmente imagética. Um lócus em que, na visão de Baudrillard (2001, p. 12), tudo é mostrado (como no Big Brother e em outros reality shows, etc.), o que nos leva a perceber que não há mais nada a ser visto:

é o espelho da platitude, do grau zero, onde se comprova, contrariando todos os objetivos, o desaparecimento do outro e talvez mesmo do fato de que o ser humano não é fundamentalmente um ser social. O equivalente a um readymade - transposição exata da vida de todo dia, ela mesma já falsificada por todos os modelos dominantes. Banalidade sintética, fabricada em circuito fechado e sob tela de controle.

O site Chatroulette enfatiza em sua interface o uso de webcams e equilibra a sua diagramação concedendo espaços semelhantes à informação escrita e às imagens em movimento. Os usuários, na busca da contemplação das imagens humanas seguintes, vão sendo conectados uns aos outros de forma aleatória e só em alguns casos desenvolvem uma comunicação escrita ou oral - diferentemente do que acontece em outros chats nos quais os acessos podem ser direcionados de acordo com a idade ou o país de residência, por exemplo, além dos nicks que dão pistas sobre os interesses dos usuários. No Chatroulette, cabe aos próprios internautas selecionarem com quem vão iniciar e manter, ou não, uma conversação, dentro das opções que vão sendo apresentadas pelo sistema. Esses princípios de igualdade e ausência de critérios seletivos prévios, propostos pelo mecanismo do site, propiciam um ambiente que, embora para alguns seja assustador, para outros é tido como "neutro e seguro" - no qual o usuário emite ao restante daquele universo uma imagem sua buscando aceitação, mas também se encontra na condição de aceitar ou não o outro, sem comprometer-se. 
Um paralelo dessa realidade foi muito bem expresso nas palavras de Baudrillard (2001, p. 12) quando comentou a exposição desenfreada da vida cotidiana por meio da "banalidade mortífera" dos reality shows:

no fundo tudo isso corresponde ao direito e ao desejo imprevisível do ser imprescritível. De não ser nada e de ser visto como tal. [...] Tornamo-nos nulos para ser vistos e considerados como nulos - proteção definitiva contra a necessidade de existir e a obrigação de ser. Daí a exigência contraditória e simultânea de não ser visto e de ser perpetuamente visível.

Como todo processo de absorção de um estímulo externo, as análises das imagens são concluídas na mente dos receptores que, para tanto, utilizam-se de um repertório composto previamente por vivências reais ou mentais. Assim, a mensagem que uma pessoa deseja transmitir será diferente daquela finalizada na mente de quem a recebe fazendo com que ela seja aceita ou rejeitada - já que, ao mesmo tempo em que conecta pessoas sem qualquer avaliação crítica, o site (Figura 1) permite que os usuários troquem rapidamente a pessoa que lhe foi proposta e tenham acesso à próxima.
O punctum, descrito por Roland Barthes em A câmara clara (1984, p. 69), comanda a ação de aceitar ou não uma pessoa simplesmente por seu vídeo. É aquele “algo" que vai além do visível e toca o leitor da imagem independentemente do que seu olhar buscava. Diferentemente do proposto por Platão, o punctum não está ligado a um distanciamento racional, mas ao afeto e às sensações que a imagem provoca. "É um detalhe," que não é procurado conscientemente, porém, que advém à mente do receptor e capta sua atenção, despertando sensações mentalmente associadas àquilo. Talvez seja justamente aí que ocorra o que Baudrillard (2002, p. 9) chama de vivissecção: "estamos a ponto de dissecar, em vivissecção, sob o escalpelo da câmera, a dimensão relacional e social, fora de qualquer linguagem e contexto simbólico".

Para atender às exigências de manutenção da sua ordem psicossocial estabelecida, o indivíduo relaciona-se, ou não, com o usuário apresentado pelo Chatroulette. A imagem passa a ser essencial para o julgamento rápido entre o estabelecimento de uma conversação ou o comando para troca de parceiro, ou seja, passa a ser mediadora das relações sociais.

Mais uma vez, cabe aqui o conceito defendido por Debord (1997, p. 14) na instauração de uma sociedade do espetáculo, visto que, na argumentação

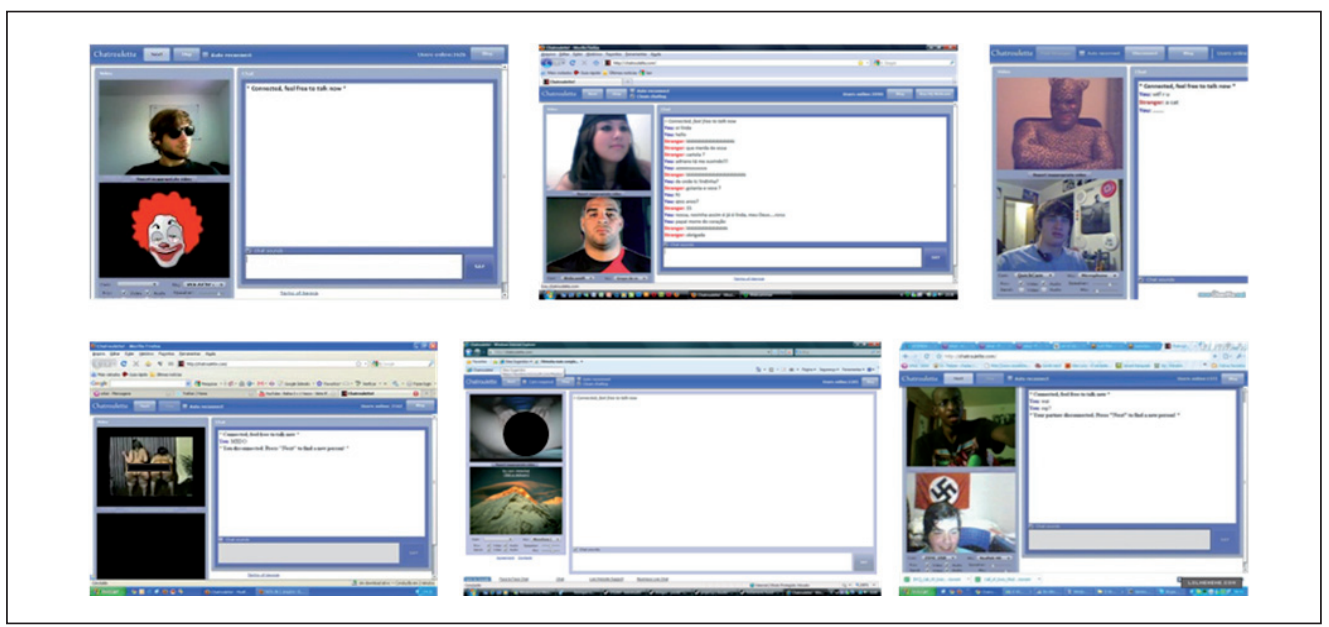

Figura 1 - Print screens do Chatroulette postados por diversos usuários na web

do autor, "o espetáculo não éum conjunto de imagens, mas uma relação social entre as pessoas, mediada pelas imagens". Acrescente-se a isso o que Silva e Tonin (2008, p. 2) comentam quando traçam um paralelo das ideias de Debord (1997) e Baudrillard
(1991), lembrando que ao mesmo tempo em que "o espetáculo de Debord é uma condenação da imagem pela alienação e massificação produzidas no social e advertência para uma imprescindível tomada de consciência (idéia do sujeito)", a ideia de Baudrillard 
sobre o hiper-real "é uma constatação da desrealização do mundo pela imagem e da impossibilidade de retorno a um estágio anterior (fim do indivíduo)".

De fato, essa realidade faz emergir uma reflexão contemporânea sobre a nova sociabilidade ${ }^{23}$ no espaço virtual, agora mediada pela subjugação da aparência. As interações no ciberespaço revelam novas formas de relacionamento, embora muitas vezes diferentes daquelas estabelecidas face a face. Contudo, isso não exclui a presença da alteridade, enquanto percepção e reconhecimento do outro, nem da existência de estigmas entre os indivíduos nesse processo (SANTOS, 2005, p. 45).

Por conseguinte, percebe-se no espaço do Chatroulette, assim como nas interações face a face, o estabelecimento de uma relação dependente das variantes físicas visíveis na imagem do outro. Rejeitam-se, desse modo, aqueles que se "afastam negativamente das expectativas particulares" (GOFFMAN, 1988, p. 14 apud SANTOS, 2005, p. 43). Logo, as relações materializadas em sites como o Chatroulette podem ser vistas de forma análoga pelas óticas de Baudrillard e Debord, que, respectivamente, revelam-se como um simulacro da vida real, contribuindo para uma sociedade do espetáculo.

Percebe-se, com isso, que a comunicação sociabilizada por meio do Chatroulette e do mundo offline é similar em muitos aspectos, mesmo considerando também o quesito do anonimato presente no primeiro. Ambos baseiam-se nos estereótipos e no status de imagens, muito embora as relações fora da web firmem-se de uma maneira mais eufêmica e menos nua e crua como no Chatroulette. Ou, em outras palavras, os indivíduos julgam e se permitem ser julgados pelo "visível" o tempo todo, independente do ambiente. Toda essa exposição revela que, diferentemente da ameaça à privacidade proposta por Orwell na obra 1984, a sociedade contemporânea vivencia o paradigma da invasão consentida e desejada.

\section{Referências}

ALCARÁ, A. R.; DI CHIARA, I. G.; TOMAÉL, M. I. Das redes sociais à inovação. Ciência da Informação, v. 34, n. 2, p. 93-104, 2005.

ARAÚJO, L. Sociabilidade. 2009. Disponível em: $<$ http://recantodasletras.uol.com.br/artigos/1592646>. Acesso em: 18 mar. 2010.

BALLONE, G. J. Compulsão à internet, mito ou realidade. 2003. Disponível em: <http://glollone.sites.uol. com.br/temas/internet.html>. Acesso em: 3 mar. 2010.

BARTHES, R. A câmara clara: nota sobre a fotografia. Rio de Janeiro: Nova Fronteira, 1984.

BAUDRILLARD, J. Simulacros e simulação. Lisboa: Relógio D’Água, 1991.

BAUDRILLARD, J. Banalidade mortífera. Folha de S. Paulo, 10 jun. 2001. Caderno Mais!, p. 12-13.

BAUDRILLARD, J. Big Brother: telemorfose e criação de poeira. Revista FAMECOS, n. 17, p. 7-17, 2002. Disponível em: <http://revistaseletronicas. pucrs.br/ojs/index.php/revistafamecos/article/ viewFile/3148/2419>. Acesso em: 3 mar. 2010.

BAUMAN,Z.Éticapós-moderna.SãoPaulo:Paulus, 1997.

BIERNAZKI, W. E. Globalização da comunicação. Comunicação \& Educação, n. 19, p. 46-65, 2000. Disponível em: $<$ http://revcom2.portcom.intercom.org. br/index.php/Comedu/article/viewFile/4473/4195>. Acesso em: 28 mar. 2009.

BIRMAN, J. Mal-estar na atualidade: a psicanálise e as novas formas de subjetivação. 2. ed. Rio de Janeiro: Civilização Brasileira, 2000.

BRUNO, F. Quem está olhando? Variações do público e do privado em weblogs, fotologs e reality shows. Contemporanea - Revista de Comunicação e Cultura, v. 3, n. 2, p. 53-70, 2005. Disponível em: <http://www. portalseer.ufba.br/index.php/contemporaneaposcom/ article/view/3461>. Acesso em: 05 mar. 2010.

\footnotetext{
${ }^{23}$ Bauman (1997, p. 138) esclarece as diferenças entre os termos "socialização" e "sociabilidade", considerando que ambos devem ser compreendidos a partir da interação com a estrutura social, mesmo que se refiram a processos distintos. Para Bauman, a socialização (pelo menos na sociedade moderna) visa a criar um ambiente de ação feito de escolhas passíveis de serem 'desempenhadas discursivamente', que se concentra no cálculo racional de ganhos e perdas. Já na visão do autor, a sociabilidade deve ser compreendida a partir da interação com a estrutura social, e se referem a processos distintos, sendo observada uma emergência da multidão, na qual os indivíduos compartilham ações baseadas no instante em que se vive e nas condições semelhantes nas quais se encontram (ARAÚJO, 2009).
} 
CASTELLS, M. A sociedade em rede. São Paulo: Paz e Terra, 1999.

CURVELO,P.Chat Roulette reúne mais de 35 mil membros em simultâneo. Diário Digital, 22 fev. 2010. Disponível em: <http://diariodigital.sapo.pt/news.asp?section_ id=18\&id_news=436763 . Acesso em: 3 mar. 2010.

DEBORD, G. A sociedade do espetáculo. Rio de Janeiro: Contraponto, 1997.

DUPAS, G. Tensões contemporâneas entre o público e o privado. São Paulo: Paz e Terra, 2003.

KING, S. A. Is the internet addictive or are addicts using the internet? 1996. Disponível em: <http://rdz. stjohns.edu/ storm/iad.html>. Acesso em: 3 mar. 2010.

LÉVY, P. A inteligência coletiva: por uma antropologia do ciberespaço. São Paulo: Loyola, 1998.

MAFRA, R. Entre o espetáculo, a festa e a argumentação: mídia, comunicação estratégica e mobilização social. Belo Horizonte: Autêntica, 2006.

MERIGO, C. Chatroulette: humanos aleatórios e (quase sempre) pelados. ProXXIma, Blog Século 2.1, 22 fev. 2010. Disponível em: <http://www.proxxima.com.br/ portal/post/9452>. Acesso em: 4 mar. 2010.

MICHAELIS. Dicionário escolar: língua portuguesa. São Paulo: Melhoramentos, 2008.

NICOLACI-DA-COSTA, A. M. Primeiros contornos de uma nova "configuração psíquica". Cadernos CEDES, v. 25, n. 65, 2005. Disponível em: <http:// www.scielo.br/scielo.php?script=sci_arttext\&pi $\mathrm{d}=$ S0101-32622005000100006 > . Acesso em: 2 mar. 2010.

PRADO, O. Z. Pesquisa internet e comportamento: fatores relacionados ao uso patológico de internet. 1999. Pôster. Disponível em: <http://www.psico.net/textos/ poster.html>. Acesso em: 3 mar. 2010.

PRIMO, A. Interação mediada por computador: comunicação, cibercultura, cognição. Porto Alegre: Sulina, 2007.

PRIMO, A. A busca por fama na web: reputação e narcisismo na grande mídia, em blogs e no Twitter. In: CONGRESSO BRASILEIRO DE CIÊNCIAS DA COMUNICAÇÃO, 32., 2009, Curitiba. Anais eletrônicos... São Paulo: Intercom, 2009. Disponível em: <http:// www.intercom.org.br/papers/nacionais/2009/resumos/ R4-1950-1.pdf>. Acesso em: 4 mar. 2010.

RUBIM, A. A. C. Espetáculo, política e mídia. In: ENCONTROANUALDAASSOCIAÇÃONACIONAL DOS PROGRAMAS DE PÓS-GRADUAÇÃO EM COMUNICAÇÃO-COMPÓS, 11.,2002, Rio de Janeiro. Anais... Rio de Janeiro: COMPÓS, 2002.

SANTOS, H. Alteridade, decepção e estigma no ciberespaço: desdobramentos da interação social mediada. Revista FAMECOS, n. 26, p. 41-46, 2005. Disponível em: <htp://revistaseletronicas.pucrs.br/ojs/index.php/ revistafamecos/article/viewFile/3301/2558>. Acesso em: 10 mar. 2010.

SANTOS, H. H. de C. et al. A publicidade e os recursos da realidade aumentada. In: SIMPÓSIO NACIONAL DA ABCIBER, 3., 2009, São Paulo. Anais... São Paulo: ABCiber, 2009.

SÉNECA, H. Videoconferência com estranhos? O Chatroulette arranja. Exame Informática, 2010. Disponível em: <http://aeiou.exameinformatica. $\mathrm{pt} /$ videoconferencia-com-estranhos-o-chatroulettearranja $=$ f1005150>. Acesso em: 3 mar. 2010.

SILVA, J. M. da; TONIN, J. Espetáculo, simulacro, tribalismo e hipermodernidade: os paradoxos da sociedade da imagem. In: MOSTRA DE PESQUISA DA PÓS-GRADUAÇÃO - PUCRS, 3., 2008, Porto Alegre. Anais eletrônicos... Porto Alegre: EDIPUCRS, 2008. Disponível em: <http://www.pucrs.br/edipucrs/ online/IIImostra/ComunicacaoSocial/63029\%20-\%20 JULLIANA\%20TONIN.pdf> . Acesso em: 10 mar. 2010.

SOUZA, A. Twitter: publicidade em 140 caracteres. 2009. Trabalho de conclusão de curso (Graduação em Publicidade e Propaganda) - Universidade Federal Pernambuco, Recife, 2009.
Recebido: 23/03/2010

Received: 03/23/2010

Aprovado: 23/04/2010 Approved: 04/23/2010 